fixation of complement. ${ }^{1}$ The ice-box fixation can therefore be used only as a presumptive test to eliminate the negative cases. ${ }^{2}$

3. As for fixation of complement at temperatures below the freezing point we find that such a procedure produces undesirable changes in the reagents, especially in the antigen and is therefore unsuitable for the test.

$$
84 \text { (1262) }
$$

\title{
A study of the acid-base equilibrium of the blood in acute bichloride intoxications. ${ }^{3}$
}

BY WM. DEB. MACNIDER.

[From the Laboratory of Pharmacology of the University of North Carolina.]

Thirty-two dogs have been used in the initial series of experiments. The animals were kept in metabolism cages, given 500 c.c. of water by stomach tube and fed on bread with a small amount of meat. The urine was examined qualitatively for albumin, acetone and glucose. The hydrogen ion (p. H.) concentration of the blood was determined by the method of Levy, Rowntree and Marriott, and the alkali reserve of the blood (R. p. H.) and the tension of alveolar-air carbon dioxide by the methods of Marriott. The phenolsulphonephthalein test was conducted according to the method of Rowntree and Geraghty.

The urine during two days of observation prior to the administration of the bichloride was normal. The hydrogen-ion content of the blood varied between 7.4 to 7.5 , the reserve alkali between 8.05 to 8.I, while the tension of carbon dioxide in alveolar air has shown a variation between 40 to $45 \mathrm{~mm}$. The total output of phthalein in a two-hour period has varied from 74 to 9I per cent.

The animals were starved for twenty-four hours prior to giving the bichloride. On the days of the experiments the animals were given 0.25 c.c. of a 4 per cent. solution of morphine sulphate

1 Bronfenbrenner and Schlesinger, Proc. Soc. Exp. Biol. AND MEd., igr6, XVI, p. 37 .

Bronfenbrenner and Schlesinger, Am. Jour. of Spyhilis, April, I9r7.

3 The expense of the investigation has been aided by a grant from the Rockefeller Institute for Medical Research. 
subcutaneously. After the initial emesis the animals became drowsy and during this period $15 \mathrm{mg}$. per kilogram of bichloride of mercury was given by stomach tube. With four exceptions no vomiting occurred from the local irritant effect of the mercury.

Within twenty-four hours all of the animals developed a severe gastro-enteritis. The stools were frequent and bloody. The severity of the enteritis has varied in different animals. There is no definite relation between the severity of the gastroenteritis and the delayed toxic effect from the poison. The variation in the toxic effect of bichloride in the different experiments permits the following classification of the animals.

Group I.-Six animals. An intense gastroenteritis. The animals are in much pain, cold, tongue bluish, unable to walk. Apparently in collapse. All of the animals in this group which is characterized by the early and intense gastroenteritis have died within forty-eight hours following the bichloride.

The urine in this group is reduced in amount. The lowest output in twenty-four hours has been 9I c.c. With one exception, the urine of these animals has been free from albumin, glucose and acetone. The urine of one of the animals contained less than $0.5 \mathrm{gm}$. of albumin per liter (Esbach). In this group of animals which apparently die from the shock associated with the intense local action of the bichloride, the hydrogen-ion content of the blood has not gone higher than 7.35. The reserve alkali of the blood and the tension of alveolar air carbon dioxide have not varied from the normal. The phthalein output has been uniformly slightly reduced.

Group 2.-Nine animals. All of the animals have developed a severe gastroenteritis. During the subsidence of the enteritis or several days after the symptoms of the enteritis had disappeared, the animals have shown an increase in the hydrogen ion content of the blood which in one animal went as high as 7.3. The alkali reserve of the blood has shown a depletion. In none of the animals have the determinations been below 7.9. The tension of carbon dioxide has not gone below $35 \mathrm{~mm}$. In this group of animals the phthalein output has shown a greater reduction than in Group I. The total output has varied between 5I to 63 per cent. The urine has contained as much as $1.5 \mathrm{gm}$. of albumin per liter. No acetone or glucose. 
Following these indications of a mild acid intoxication and an associated kidney injury, the acid-base equilibrium of the blood has gradually returned to the normal, the output of phthalein has increased, the albumin has disappeared or has been reduced to a trace and all of the animals have recovered.

Group 3.- Seventeen animals. Following the subsidence of the mercury enteritis, and in the case of two of the animals, as late as six days after these symptoms had disappeared, the animals have either very rapidly (within eight hours), or gradually, developed a severe acid intoxication and died. The highest hydrogen ion concentration of the blood in this group has been 7.r. The reserve alkali of the blood in this animal was reduced to 7.7 , while the tension of alveolar air carbon dioxide was $18 \mathrm{~mm}$. The animal died in air hunger.

With the development of an acid intoxication the output of urine is greatly reduced or the animal is rendered anuric. The phthalein output shows a rapid reduction. In the animal above referred to the output of phthalein was only ro per cent. The urine in this group of animals has contained as high as $2.75 \mathrm{gm}$. of albumin per liter and in all of the animals the urine has contained both glucose and acetone. Casts have not been numerous.

The kidneys of those animals which succumb during the height of the gastro-enteritis from bichloride are uniformly and severely congested. The kidneys appear cyanotic. The epithelium shows but slight evidence of damage. The cells of the ascending limb of Henle's loop show a small amount of fat.

The kidneys of those animals which die after the subsidence of the enteritis and during a period of acid intoxication have a pale, anemic appearance and show a clear-cut fatty zone at the cortico-medullary junction. The tubular epithelium, and especially that of the convoluted tubules, is severely swollen, vacuolated and rapidly becoming necrotic. The cells of the ascending limb of Henle's loop show a severe fatty infiltration.

\section{Conclusions.}

I. The acute kidney injury which develops late in poisoning by bichloride of mercury does not show any dependence in the frequency with which it occurs with the severity of the mercury enteritis. 
2. The delayed kidney injury in acute bichloride intoxications has been constantly associated with the development of an acid intoxication. The severity of the damage to the cells of the convoluted tubules and the extent of fatty infiltration in the cells of the ascending limb of Henle's loop show a correlation with the degree of acid intoxication.

\section{$85(1263)$}

Relation of the spinal cord to the spontaneous liberation of epinephrin.

\section{By G. N. Stewart and J. M. Rogoff.}

[From the H. K. Cushing Laboratory of Experimental Medicine, School of Medicine, Western Reserve University, Cleveland.]

I. In acute experiments on cats, anesthetized with urethane, section of the spinal cord in the cervical region caused no demonstrable diminution in the rate of liberation of epinephrin from the adrenals as tested by allowing the adrenal blood collected in a cava pocket to elicit eye-reactions (after preliminary excision of the superior cervical ganglion). Four such experiments were made. The cord section in one of these was between the third and fourth cervical vertebræ, in another opposite the body of the fourth cervical vertebrae, in a third just below the body of the fifth cervical vertebra, and in a fourth cat between the fifth and sixth cervical vertebræ. In the second of these animals the blood was collected from the adrenal vein before and after section of the cord. The epinephrin assay (by rabbit intestine segments) gave the same output of epinephrin per minute after as before the section. The blood flow from the adrenals was much slower after the section, but was correspondingly richer in epinephrin.

2. In two survival experiments the cord was cut in the cervical region (in one just above the body of the last cervical vertebra, in the other at the level of the body of that vertebra). In the first cat, the superior cervical ganglion had been previously excised. Two days after the cord section adrenal blood was tested by the cava pocket method and gave good eye reactions, indicating 